\title{
ГОСУДАРСТВЕННЫЕ ИНВЕСТИЦИИ И РАЗВИТИЕ ПАРТНЕРСКИХ ОТНОШЕНИЙ В ПОСТКОРОНАКРИЗИСНЫЙ ПЕРИОД
}

\author{
(c) 2021 Зельднер Алексей Григорьевич \\ доктор экономических наук, профессор \\ главный научный сотрудник \\ Институт экономики РАН, Россия, Москва
}

В статье рассматриваются проблемы, связанные с возможностью мобилизации внутренних инвестиционных источников в условиях постковидного периода и растущих санкций. Механизм их конвертации в крупные инфраструктурные проекты лежит в развитии партнерских отношений государства и бизнеса, и в этом плане активизация использования в увеличенном масштабе госинвестиций может стать важнейшим стимулом для привлечения частных инвестиций в воспроизводственный процесс.

Ключевые слова: партнерские отношения, бюджет, фонд национального благосостояния, золотовалютные резервы, инфраструктура, экономический рост.

\section{Введение}

Становление партнерских отношений в современной России относится к началу XXI века, и с тех пор, не без проблем, но развивается. Развитие рыночных отношений и становление частной собственности привело к увеличению удельного веса частных инвестиций в основном капитале почти на треть, и это при одновременном росте социальной нагрузки на государство, что потребовало также роста инвестиционных затрат.

Партнерские отношения государства и бизнеса исторически возникли достаточно давно, с момента появления государства. Интересы государства и частных предпринимателей постоянно пересекались, особенно в обеспечении инфраструктурой, и принимали различные формы в зависимости от внешних и внутренних факторов, определяющих финансовое положение стран. Партнерским отношениям свойственна система аддитивности (лат. «прибавляемый»). Это означает отношения, при которых свойства целого определяются свойствами его частей.

С теоретических позиций государственночастное партнерство (ГЧП) - важнейший элемент смешанной экономики и одновременно важнейший рычаг госрегулирования, уровень которого определяется состоянием и целями социальноэкономического развития. Партнерство государства и бизнеса в условиях становления рыночных отношений предполагают толерантное отношение между субъектами рынка и институтами гражданского общества, направленное на обеспечение социально-экономического роста на базе структурной модернизации, инновационного развития и социализации общественных отношений.

В процессе партнерских отношений в зависимости от социальной направленности реализуемых инфраструктурных объектов государство включается в рыночные отношения, наряду с обеспечением общества услугами, рассчитывая не только на окупаемость проекта, но и на возможное получение прибыли. Так что, когда мы говорим о партнерских отношениях, они предполагают наряду с удовлетворением общественных благ и реализацию экономических интересов субъектов партнерских отношений. При этом следует учитывать, что, как правило, государство, исходя из национальных целей, определяет общий тренд приоритетных проектов, что и предполагает заключение ГЧП. И главное права собственности, именно государство в значительной мере определяет основные направления ее дальнейшего использования. Речь в основном идет о праве владения и пользования объектами собственности бизнесом, а право распоряжения остается в основном за государством.

Формирование партнерских отношений предполагает определенный паритет при подходе к реализации тех или иных проектов, но не диктат одного из партнеров. Это достаточно тонкая в психологическом отношении проблема, от компромиссного решения которой зависит приток частных инвестиций в экономическое развитие страны. Между тем, даже в ковидокри- 
зис, система диктата государства не снимается. По мнению министра финансов А.Силуанова, «Мы сейчас предложили, чтобы на рубль ФНБ мы могли бы привлекать не менее пяти рублей частных инвестиций и более. И тогда это будет синергия. И тогда действительно мы можем говорить о том, чтобы задействовать и частные инвестиции, и стимулировать новые проекты, новые рабочие места»*. Привлекая частный бизнес в крупные проекты, Минфин уточнил, «что разделение рисков между государством и бизнесом возможно только в проектах, в которых государство «крайне заинтересовано». Следует отметить, что установление паритетной ответственности по рискам для частного капитала исключительно важный стимул его участия в партнерских проектах.

Опыт становления партнерских отношений в России и особенно анализ эффективности работы в стране особых экономических зон (ОЭЗ) показал, что существует достаточно тесная взаимосвязь между объемом выделяемых бюджетных средств на строительство инфраструктуры для ОЭЗ и объемом привлекаемых резидентами частных инвестиций. Существенное снижение бюджетного финансирования ОЭ3, начиная с 2012 г., привело к уменьшению притока и частных инвестиций**.

Структурная перестройка экономики России на базе смены модели развития, переход от сырьевой на индустриально-инновационную модель развития - объективный процесс. Оценивая общую ситуацию, сложившуюся со структурной модернизацией на инновационной основе, рассмотрим сложившуюся ситуацию с учетом финансовых возможностей государства с целью увеличения инвестиционных вложений государства в бизнес-проекты на условиях ГЧП.

Государственные источники инвестиционных ресурсов: состояние и возможности

Как известно, наличие инвестиций при грамотном использовании обеспечивает социальноэкономическое развитие. Стагнируют инвести- ции - то же происходит и с развитием. И не случайно Президент страны акцентирует внимание правительства на повышении инвестиционной активностин**. Как известно, снижение ВВП в 2020 г. составило в стране 3,0\%, и не последнюю роль в этом сыграли инвестиции. Инвестиции в основной капитал в 2020 г. составили 20118,4 млрд. руб., это 98,6\% от суммы 2019 г. Причем наибольшее снижение инвестиций по отношению к 2019 г. произошло в Дальневосточном федеральном округе - 87,4\%. Падение ниже 90\% отмечается в 26 субъектах РФж****.

Следует учитывать, что снижение инвестиционной активности в регионах страны на данном этапе развития определяется в основном коронакризисом. Существенную роль играет и дефицит федерального и консолидированного региональных бюджетов и санкции, ограничивающие использование иностранных инвестиций. Более того, федеральный бюджет на ближайшие три года (2021-2023 гг.) планируется как дефицитный. При этом современные рыночные условия изменили структуру инвестиций. Все больший удельный вес в общей структуре инвестиций в основной капитал занимают частные вложения. Так, если в 2000 г. частные инвестиции в основной капитал составляли 29,9\%, в 2010 г.- 57,0\%, то в 2018 г. они достигли 60,9\%*****.

Правительство страны обозначило ряд направлений стимулирования привлечения частных инвестиций в проекты ГЧП, которые включают использование механизмов, связанных как с продолжительно фиксированной налоговой ставкой, так и с компенсацией затрат инвесторов за счет будущих налогов, (по сути, механизм отложенных налоговых платежей (TiF). Планируется и увеличение компенсации региональным бюджетам инвестиционного вычета по реализуемым проектам за счет федеральных источников. Кроме того, правительство планирует расширить доступ инвесторам к финансовым ресурсам, включая кредиты и облигационные займы. Речь идет о приоритетных проектах.

\footnotetext{
* Маркелов Р. Как цели оправдывают средства. Российская газета 12.03.2021.

** Зельднер А.Г.Деструктивные тенденции и конструктивные возможности их преодоления в экономической системе России. М. Экономика. 2013. С. 101-127. Проведенный нами анализ по материалам сводных годовых отчетов ОЭЗ подтверждает этот вывод.

*** По мнению Президента, инвестиции в основной капитал России должны вырасти на $70 \%$ к 2030 году по сравнению с 2020. (Российская газета. 12.03.2021. С. 2).

**** Основные показатели социально-экономического положения субъектов РФ в 2020 г. Российская газета. 12.03.2021. С. $10-11$.

***** Инвестиции в России 2019. Росстат. М. 2019. С. 41. Инвестиции в России 2009. Росстат. М. 2009. С. 47.
} 
Планы обнадеживают, остается только обеспечить их реализацию, что можно будет проследить по темпам роста привлеченных инвестиций. В этом ключе мы рассмотрим возможности государственных источников: бюджета, фонда национального благосостояния, золотовалютных резервов и других источников.

\section{Бюджетные источники России}

Коронакризис внес существенные изменения в состояние федерального и региональных бюджетов. Дефицит федерального бюджета в 2020 г. составил 4,1 трлн. руб., это 3,8\% ВВП страны. «При доходах в 18,72 трлн. руб. расходы составили 22,82 трлн. руб. Дефицит в 4,1 трлн. руб. был закрыт масштабным заимствованием, объем которого отклонился от плана в 2,6 раза»*.

Что касается состояния бюджетов регионов РФ, то их консолидированный бюджет, по данным зам. министра финансов Л.Горюнова, исполнен с дефицитом в 677 млрд. руб., из них 83\% пришлись на 16 регионов с высокой долей ТЭК, плюс Москва, Московская область и Петербург. Госдолг субъектов вырос на 18\% до 2496 млрд. руб ${ }^{* *}$. Большинство российских регионов завершили 2020 г. с дефицитом бюджета (58 из 85), это $68,2 \%$, в том числе такие регионы как Тюменская область (-20\%), Кемеровская область (-21\%) и др.

По данным Счетной платы, государственный долг России в 2020 г. увеличился на 39,9\% (5,42 трлн. руб.). Теперь он составляет 18,99 трлн., что составляет почти $18 \%$ ВВП***. «Увеличение объема государственного долга Российской Федерации в основном связано со значительными объемами внутренних заимствований»,- отмечается в докладе Счетной палаты РФ. Наряду с дефицитом консолидированного бюджета страны в 2020 г. планируется, что федеральный бюджет на 2021-2023 гг. также останется дефицитным. В 2021 г. дефицит составит 2,75 трлн. руб.
(2,4\% ВВП), в 2022 г. $-1,25$ трлн. руб. (1\% ВВП), в 2023 г. $-1,41$ трлн. руб. $(1,1 \% \text { ВВП) })^{* * * * * *}$

Трехлетним федеральным бюджетом на 2021-2023 гг. планируется выделение на национальные проекты 7,6 трлн. руб. и более 2,5 трлн. руб. на развитие дорожной сети, а с учетом региональных дорожных фондов эта сумма превысит 6 трлн. руб. Кроме того, на восстановление экономики в посткризисный период на 2021 г. выделяется 638,9 млрд. руб.******* (Федераль ный закон от 8 декабря 2020 г. № 385-ФЗ «О федеральном бюджете на 2021 г. и на плановый период 2022 и 2023 годов».).

Фонд национального благосостояния (ФНБ)

Средства консолидированного бюджета четко расписаны, а самые крупные резервы государства сосредоточены в ФНБ. На начало 2021 г. объем ликвидных активов ФНБ составлял 7,5\% ВВП, В 2020 г. объем ВВП России в текущих ценах составил 106965 млрд. руб. В соответствии с бюджетным правилом при превышении ликвидной части ФНБ 7\% ВВП часть его средств может быть использована на инвестпроекты. И эта ситуация реальна - средства ликвидной части ФНБ превышают уровень 7\%. В ходе совещания по вопросам инвестиционной активности в начале 2021 г.******** президент подчеркнул: «Прошу правительство в месячный срок представить конкретные предложения по инвестированию средств ФНБ, в том числе в инфраструктурные проекты». Также президент распорядился провести инвентаризацию проектов и выяснить, какие из них в достаточной мере проработаны, а также определиться с тем, в какие из них стоит инвестировать. Имеется опыт США, и более современный опыт Китая, когда в кризисных условиях средства концентрируются на инфраструктурных объектах, в первую очередь, на дорожномстроительстве ${ }^{* * * * * * * * * * *}$, аэтовозможностидля

\footnotetext{
* Горнин Л. Состояние стабилизировалось. Российская газета. 29.01.21.

** Виспогузов В.Бюджет освоил коронакризис. Коммерсант № 10 от 22.01.2021. https://www.kommersant.ru/ doc/4654850.

В то же время, по данным Счетной палаты РФ, в 2020 г. российские ведомства не смогли использовать 1,2 триллиона рублей бюджетных средств (https://ach.gov.ru/audit/oper-2020). Не использованы 443 млрд. руб. на общегосударственные проблемы, 139 млрд. руб. на оборону, 69 млрд. руб. на ЖКХ и др.

**** https://ura.news/news/1 052473081

**** Маркелов Р. В порядке цифр. Российская газета. Столичный выпуск. № 280 (8334) htpps://rg.ru/2020/12/10/ kakim-budet-novyj-federalnyj-biudzhet-na-tri-goda.html

***** Там же.

******* https://www.mk.ru/politics/2021/03/11/putin-poruchil-nachat-tratit-dengi-iz-fnb.html

******** В России 55 тысяч «убитых» дорог, из которых по 44 тысячам невозможно проехать (Аи Ф. № 11. 2021). Данные М.Блинкина, одного из самых серьезных аналитиков дорожных проблем.
} 
пространственного развития территорий и туризма со всей сопутствующей инфраструктурой и ростом занятости населения.

Но в России при распределении инвестиций срабатывает известное библейское правило: «Много званых, но мало избранных». В конце прошлого 2020 года, как сообщал «Рамблер», СМИ обнародовали утвержденный правительством общенациональный план российской экономики, который предполагает «отказ от нефтяной иглы». Документ описывает ускорение импортозамещения, развитие индустрии легкой промышленности и внутреннего туризма, цифровизацию госуправления и т.д. Результатом принятых мер должен стать среднегодовой рост ВВП на уровне 3-5\%*.

Одиночные примеры эффективного использования ФНБ в стране имеются. Причем эти примеры лежат в тренде смены модели развития, ухода от сырьевой модели, перехода на экспорт конечной продукции, а не сырой нефти. «В 2015 году компания «Сибур» получила кредит из средств фонда в размере 1,75 млрд. долларов на строительство крупного предприятия «ЗапСибНефтехим» в Тобольске со ставкой $2 \%$ годовых. На тот момент, когда значение ключевой ставки ЦБ РФ было двузначным, это были очень дешевые деньги, которые помогли «Сибуру» завершить свой проект в срок. Комплекс «ЗапСибНефтехим» был введен в строй в 2019 году - и спустя год, благодаря его мощностям, Россия впервые стала чистым экспортером двух главных базовых полимеров: линейного полиэтилена низкой плотности и полиэтилена низкого давления»**. Желающих получить часть средств ФНБ достаточно много, это: почта России, РЖД, гражданская авиация и др. Но правительство пока держится. Разум подсказывает: если делать, то по-крупному. Минфин считает, что средства ФНБ должны использоваться только в надежных финансовых инструментах без риска для бюджета.

Проблема эффективного использования ФНБ носит в значительной мере правовой и, следовательно, политический характер. До сих пор в стране нет четкого правового регулирования ФНБ (и соответственно золотовалютных резервов). По данным члена ассоциации юристов России А.Нилова «В Бюджетном кодексе есть лишь короткая новелла, посвященная ФНБ, а в законе о Центробанке несколько слов о резервах. То есть значительная часть национального богатства находится вне правового поля. В том, как формируются, учитываются, размещаются, а главное, расходуются эти триллионы - ни контроля, ни порядка, ни ответственности. Поэтому необходимы специальные законодательные акты, в которых будут прописаны принципиальные моменты, касающиеся ФНБ и резервов, включая контроль со стороны Госдумы» ${ }^{* * * * *}$.

С ростом ФНБ в стране появляются предложения о его использовании для кредитования зарубежных стран (Аи Ф. № 14. 2021). Но ведь это рентный фонд, полученный в основном от реализации природных ресурсов - национального достояния населения всей страны. Можно часть средств направить на поддержку пенсионного фонда и возобновить выплаты работающим пенсионерам (примерно 7 млн. человек), мы же вкладываем деньги в зарубежные ценные бумаги и несем убытки из-за, например, обесценивания юаня. Но мы не используем средства на поддержку населения, боясь инфляции, которую сложно остановить административными методами.

В целом следует отдавать себе отчет в том, что основная часть средств, накопленных в ФНБ рентного происхождения. Следовательно, это национальное достояние населения страны, которое необходимо использовать для поддержки безопасности, строительства инфраструктурных объектов и других потребностей страны.

\section{Золотовалютные резервы России}

Важным источником пополнения инвестиционной базы партнерских отношений в реализации инфраструктурных проектов ${ }^{* * * * * *}$ может стать использование части золотовалютных резервов. Как указывается на сайте ЦБ России,

\footnotetext{
* https://finance.rambler.ru/economics/46009237-v-rossiyskoy-ekonornike-zavershilas-retsessiya/

** Кувырко М.Куда потратить накопленный Россией огромный «мешок с золотом». https://vz.ru/ economy/2021/3/16/1089534.html

*** Там же.

**** По данным МЭР, без существенного развития инфраструктуры экономический рост России не сможет превысить 3\%. По данным ВБ, инфраструктурный фактор на 40\% определяет конкурентоспособность экономики страны. Коммерсант. Business Guide. 16.10.2014.
} 
международные резервы России по состоянию на конец 2020 г. составили 583,2 млрд. долл.*. По мнению академика РАН А.Некипелова, «... для обеспечения стабильности отечественной денежной системы необходимо максимум 100 млрд. долл.». В мировой практике объем золотовалютных резервов рассчитывается как сумма, равная объему импорта за три месяца (примерно 40 млрд. долл.) плюс объем краткосрочных выплат по внешним долгам (50-60 млрд. долл.); это, так называемый, коэффициент достаточности международных резервов.

По оценке Центробанка России, нынешний золотовалютный резерв государства чрезмерен, его размещение за рубежом приносит не слишком большие доходы, и, учитывая сложное положение в несырьевых отраслях России, в условиях коронакризиса нецелесообразно содержать сверхнормативный валютный резерв. Часть 30лотовалютного резерва возможно использовать на партнерские проекты по дорожному строительству, на создание мощностей по переработке нефти и газа, обеспечив переход на экспорт конечной продукции, а не сырья.

\section{Потенциальные источники инвестиций}

Судя по состоянию бюджетов всех уровней, и падению суммы инвестиций в основные фонды на 1,4\% в 2020 г., может сложиться впечатление о России, как стране остро нуждающейся в инвестициях. Но это поверхностное суждение, инвестиции в стране имеются. Дело в том, что часть крупного бизнеса (скорее всего, его большая часть (оценочное мнение) стремится зарабатывать «деньги на деньгах», причем в значительной части за рубежом. Так, в январе 2021 г. на Гайдаровском форуме сенсацией стало обнародованные ФНС данные о том, что «средств на депозитах резидентов РФ в банковских системах за пределами страны: это более 700 тыс. счетов 400 тыс. резидентов общим объемом более 13 трлн. руб. (порядка 170 млрд. долл.»**. Эта сумма примерно равна объему средств, находящихся в ФНБ.

Благодаря сырьевому экспорту страна в последние десятилетия больше экспортировала, чем импортировала. По имеющимся данным, это обеспечило «больше 200\% кумулятивного роста, но учтенные активы, государственные и частные, росли гораздо медленнее. Причиной было бегство капиталов. Оффшорное богатство, принадлежащее российским хозяевам, составляет 800 млрд. долларов»***. По курсу начала ноября 2020 г. 1 долл.=80 руб. Сумма вывоза капитала составила 64 трлн. руб. Это примерно в два раза выше доходной части консолидированного бюджета страны за 2018 г.

Вывоз капитала оказывает существенное влияние на неравенство. По оценке французского экономиста Тома Пикетти, «1\% россиян контролируют четверть национального дохода. Согласно этой оценке, неравенство в России примерно равно неравенству в США, выше неравенства во Франции и почти вдвое выше неравенства в Китае. В докладе Credit Suisse за 2015 год неравенство в России оценивалось еще выше: в России 10\% домохозяйств владеют 87\% всего национального богатства; в Штатах - 76\%, в Китае - 66\%. Согласно оценке Форбса, сотня российских миллиардеров владеет капиталами, которые в сумме превышают накопления всех остальных граждан»****.

Следует отметить, что проблема вывоза капитала из России периодически поднимается руководством. Выступая в марте 2021 г. на коллегии Генпрокуратуры, Президент страны потребовал вернуть украденное из-за границы обратно в Россию и не тратить больше, чем зарабатывают чиновники. «Нужно выявлять несоответствие расходов муниципальных и госслужащих их доходам. На повестке дня и совершенствование механизмов возврата из-за рубежа активов, полученных преступным путем»,- подчеркнул Путин ${ }^{* * * * * * . ~ Д л я ~ в о з в р а т а ~ н е з а к о н н о ~ в ы в е з е н-~}$ ных средств под руководством Генпрокуратуры РФ создана межведомственная рабочая группа.

На фоне борьбы за возврат из-за рубежа незаконным путем полученных средств не совсем понятен маневр Минфина по увеличению вложений в ценные бумаги США, учитывая остроту положения с инвестициями в России и достаточно сложные отношения между странами в настоящее время. «Россия в январе 2021 г. уве-

\footnotetext{
*https://russian.rt.com/business/news/809416-cb-rossiya-mezhdunarodnye-rezervy

** Коммерсант. № 5. 2021. Батурин Д. Вирус уходит, но не прощается. https: www.kommersant.ru/doc/4642207.

*** Эткинд А. Природа зла. Сырье и государство. М.: Новое литературное обозрение. 2020. С. 454

**** Там же.

***** Путин потребовал от чиновников вернуть наворованное... MK Ru. 21.03.2021 https://www.mk.ru/ politics/2021/03/21/putin-potreboval-ot-chinovnikov-vernut-navorovannoe-spektakl-nachinaetsya.html
} 
личила объем вложений в американские казначейские ценные бумаги (US Treasuries) до 6,145 млрд. долл., в декабре 2020 года он был на уровне 6,011 млрд. долл.», следует из данных (https.// ticdata.treasury.aov/Publish/slt3d.txt) Минфина США. На долю долгосрочных облигаций пришлось 2,7 млрд. долл., месяцем ранее было 1,2 млрд. долл. На долю краткосрочных - 3,4 млрд. долл. по сравнению с 4,8 млрд. долл. в декабре 2020 года. Крупнейшими держателями госбумаг США в январе стали Япония (1,27 трлн. долл.) и Китай (1,09 трлн. долл.)*.

Обострение международных отношений, рост санкций, напряжение в российскоукраинских отношениях и другие проблемы могут привести и к проблемам с внутренним долгом страны. Как известно, все страны мира, включая и Россию, выпускают облигации федерального займа. Их покупают как отечественные, так и зарубежные инвесторы. Вырученные средства идут на общенациональные проблемы. По мере завершения срока их действия ОФЗ гасят, выплачивая номинальную стоимость и обещанную маржу. По данным Банка России, «объем рынка ОФЗ по состоянию на 1 февраля 2021 г. составил 13,7 трлн. рублей, из них 3,2 трлн. рублей $(23,4 \%)$ - номинальный объем ОФЗ, принадлежащих нерезидентам»**.

Введение санкций в автоматическом режиме означает запрет на покупку иностранцами наших ОФЗ. Если продолжать размещать ОФЗ на внутреннем рынке, то это означает отток инвестиций из экономики. Так, к примеру, в 2021 г. из федерального бюджета в Пенсионный фонд страны должно было быть перечислено 3,3 трлн. руб., так как фонду не хватает своих средств для выплаты пенсий. Так что проблема санкций в отношении нашего госдолга достаточно серьезно может отразиться на расходной части бюджета страны.

Геополитика в системе расходования и возврата бюджетных средств

Один из достаточно постоянных источников денежно-материальных внешних затрат России с момента октябрьского переворота 1917 г.- это реализация крупных политических проектов и вопросы позиционирования созданной социалистической системы. Сразу после 1917 г. был провозглашен лозунг «Даешь всемирную революцию!», и Россия помогала деньгами и оружием пролетариям всех стран объединиться против всемирной буржуазии. Прошло время, история оценила наши затраты. Россия с 1990 г. строит свой капитализм, который выливается в острое неравенство между богатыми и бедными. И тем не менее, геополитические амбиции в стране сохранились, теперь они уже носят более точечные экономико-политические цели. Эксперты «Новой газеты» подсчитали, что за последние 20 лет Россия потратила «46 трлн. рублей на геополитические спецоперации», как отмечают эксперты, «на эти деньги можно было бы построить в стране 15 тысяч новых больниц или положить на накопительный счет каждого взрослого гражданина России по 400 тысяч рублей. Но вместо этого нефтяная рента утекла за рубеж: около 1 трлн. долл. оказались припаркованы в оффшоpax, a еще 609 млрд. долл. власти потратили на внешнюю политику, которая навлекла на страну международные санкции и практически лишила настоящих союзников» ${ }^{* * * *}$. Речь в первую очередь идет о инновационно развитых и самодостаточных в финансовом отношении странах.

Поддержка Белоруссии за последние 20 лет и Украины (до 2014 г.) обошлась России в 271 млрд. долл. (скидки на топливо, госкредиты), Венесуэла за последние 10 лет получила 20 млрд. долл.****. Велики и просроченные долги другим странам, которые насчитывают 116 млрд. долл. Среди них 20 млрд. долл.- страны Африки и рекордные 31,7 млрд. долл.- Куба. Большинство этих денег - еще советские активы. Чтобы претендовать на эти долги, России пришлось вступить в Парижский клуб, признать и исправно выплачивать долги бывшего СССР

В условиях коронакризиса для поддержания темпов экономического роста необходимо активизировать инвестиционную политику не только за счет пересмотра размеров неприкосновенности имеющихся фондов и валютных накоплений.

\footnotetext{
*https://www.kommersant.ru/doc/4730136

** Новая газета. 17.03.2021. Держава санкций не боится. Бюджетные затраты на образование в России запланированы в сумме 1,1 трлн. руб.

*** Титова А.Налог на величие. Новая газета 27.01.2021. https://novayagazeta.ru/articles/2021/01/27/88901-nalogna-velichie

**** Там же. С. 2 .

****** Там же
} 
В целях ускоренного восстановления в постко- за счет активизации партнерских отношений, видный период социально-экономического ро- обеспечивающих реализацию инфраструктурста необходимо активизировать инвестицион- ных проектов и ускорение темпов социальноную политику государства в значительной мере экономического развития.

\section{Библиографический список}

1. Маркелов Р. Как цели оправдывают средства. Российская газета 12.03.2021.

2. Зельднер А. Г. Деструктивные тенденции и конструктивные возможности их преодоления в экономической системе России. М. Экономика. 2013. С. 101-127.

3. Основные показатели социально-экономического положения субъектов РФ в 2020 г. Российская газета. 12.03.2021. С. 10-11.

4. Инвестиции в России. 2019. Росстат. М. 2019. С. 41. Инвестиции в России 2009 Росстат. М. 2009. С. 47.

5. Виспогузов В.Бюджет освоил коронакризис. Коммерсант № 10 от 22.01.2021. https://www.kommersant.ru/ doc/4654850.

6. Эткинд А. Природа зла. Сырье и государство. М.: Новое литературное обозрение. 2020. С. 454

7. Титова А. Налог на величие. Новая газета 27.01.2021. https://novayagazeta.ru/articles/2021/01/27/88901-nalogna-velichie 